\title{
SMALL-SCALE MUD CRAB SCYLLA SP. FATTENING IN SHYAMNAGAR, SATKHIRA
}

\author{
Md. Mijanur Rahman* \\ Fisheries Program, Caritas Bangladesh \\ 1/C, 1/A, Pallabi, Mirpur-12, Dhaka 1216, Bangladesh
}

Bangladesh has vast areas of coastlines with extensive resources that provide significant livelihoods to the coastal communities. However, coastal people particularly marginal farmers are facing challenges due to salinity intrusion from shrimp farming and frequent tidal surges, cyclones (Islam and Wahab 2005, Uddin et al. 2013, Hussain 2014). The increased salinity affects the productivity of land and production of agriculture, vegetation, freshwater fisheries and livestock resulting in the reduction of livelihoods particularly for the marginal farmers. Under this situation, mud crabs fattening has recently received attention to the coastal people due to the potential opportunity for livelihood. Because they can grow in high salinity level. Also they have high economic value and global market demand (Zafar and Siddiqui 2000, Chandra et al. 2012).

Mud crabs are found abundantly in the estuaries and tidal rivers of the Sundarban mangroves. The fishers usually collect all sizes of mud crabs during tide from the rivers of Sundarban mangroves areas, but only matured crabs have the demand to international and local consumers. Some people used to raise the immature, undersized and lean mud crabs are being kept in saline water pond for certain period to grow up to marketable size. However, the farmers could not able to exploit the full benefit of mud crabs fattening due to lack of proper technical knowledge and capital. Considering this fattening of immature mud crabs was introduced in the small lands of marginal farmers with improved management practices under a community based adaptation project aiming to promote alternative means of livelihoods. The objective of this study was to assess the performance of mud crabs fattening in salinity affected small lands of marginal farmers and its potential contribution to enhance the income of households.

The study was carried out in five farms of marginal farmers in 2011 at Shyamnagar, Satkhira, adjacent to Sundarban mangroves of Bangladesh. The size of farms varied from 5 to 20 decimals (Table 1). The farmers were trained up on crab diversity, biology and fattening techniques including liming, feeding,

*Corresponding author: mijan_nir@yahoo.com

(c) 2016 Zoological Society of Bangladesh DOI: $10.3329 /$ bjz.v44i1.30186 
maturity checking and provided financial support to start the crab fattening. The farms were prepared dividing into smaller ponds of 1.5 decimals by fencing with bamboo screens (1.5 meter height) and nylon nets. Fences were pushed into mud up to $50 \mathrm{~cm}$ depth to prevent the escape of crabs. At the beginning bottom soil was dried up allowing sunlight and treated with lime at the rate of 1.5 to $2 \mathrm{~kg}$ per pond. After seven days of liming, the farms were filled up with tidal water up to three feet. Lime was also applied during fattening period at the rate of $0.5 \mathrm{~kg}$ per pond on the basis of requirement. Mud crabs were stocked early in the morning of a sunny day and densities varied from 18 to $24 \mathrm{~kg}$ per pond (Table 1). Small trash fishes and shrimps were used as feed at the rate of 2 $\mathrm{kg}$ per day per pond and applied twice in early morning and late evening. Water was exchanged almost 30\% with tidal water through inlet and outlet at every new and full moon to maintain the quality. Maturity was checked after one week onwards by placing crabs in front of light or sunlight. Mud crabs were harvested two or three times by hand picking and started at the end of 12th day. Harvested live crabs were tied by nylon rope to avoid injuries and physical damages during transportation.

The production of mud crabs and net profit from the small farms are presented in the Table 1. The harvest of mud crabs ranged from 16.91 to 23.10 $\mathrm{kg}$ per crop per pond with an average of $19.11 \pm 2.5 \mathrm{~kg}$ per crop per pond. The mortality rates varied from five to nine percent due to proper management of farms. Zafar (2004) reported about $12 \%$ of mortality rate. Four to nine crops were yielded in a production year. Maximum crops were harvested from smaller farms. The fact is that it was easy to manage the smaller areas properly by the application of less inputs like seeds, feeds and labors, which were within the means of poor farmers. Sometimes the desired immature mud crabs for seeds were not available in time as it was dependent on natural sources hindered the timely stocking particularly in the larger farms. The average fattening period per crop was 14 days. Within this period crabs became matured and marketable size and added an extra body weight of $3.3 \%$ of the total stock (Fig. 1). The average annual net profit was US\$ 63.53 (BDT 4,955.65) from a pond ranging from US\$ 43.72 (BDT 3,410.16) to US\$ 112.41 (BDT 8,767.98) per pond.

The study revealed mud crabs fattening in salinity affected small fallow lands remarkable for income generation of the marginal farmers. The mud crabs produced in small farms was encouraging as an alternative means of livelihoods that contributed significantly to the households income. The farmers managed the crab fattening farms properly by receiving training and technical support aided them to achieve a good production. Also financial assistance was crucial to start up the farms as they hardly had the capacity to invest a bulk amount of money at once. The traditional crab fattening in small lands can be flourished into a business opportunity with proper guidance along with technical and financial inputs. Moreover, higher survival rate and faster growth rates of crabs 
can lead a cost-effective intervention in a small area (Liong 1992, Ferdoushi and Xiang-Guo 2010).

The mud crabs fattening in the small lands was thrived as an alternative means of livelihoods that played important role in income generation of marginal households of coastal areas. However, dependency on wild sources for immature mud crabs as seeds may hinder the potential of mud crabs fattening. This may have negative impact on the natural stock that can lead to overexploitation. Hence, establishment of hatchery for mud crabs seed is important for commercial fattening of mud crabs.

Table 1. Stocking and production performance of mud crabs in five farms

\begin{tabular}{|c|c|c|c|c|c|c|c|c|}
\hline \multirow{2}{*}{$\begin{array}{l}\text { Farm } \\
\text { code }\end{array}$} & \multirow{2}{*}{$\begin{array}{c}\text { Farm area } \\
\text { (decimal) }\end{array}$} & \multirow{2}{*}{$\begin{array}{l}\text { Number } \\
\text { of pond }\end{array}$} & \multirow{2}{*}{$\begin{array}{l}\text { Stocking } \\
\text { (kg/pond) }\end{array}$} & \multirow{2}{*}{$\begin{array}{l}\text { Harvesting } \\
\text { (kg/pond) }\end{array}$} & \multirow{2}{*}{$\begin{array}{c}\text { Mortality } \\
\text { (\% of stock) }\end{array}$} & \multirow{2}{*}{$\begin{array}{c}\text { Crops/ } \\
\text { year }\end{array}$} & \multicolumn{2}{|c|}{ Annual net profit } \\
\hline & & & & & & & US\$/pond & $\mathrm{BDT} /$ pond \\
\hline 1 & 5 & 3 & 20.00 & 19.40 & 5 & 6 & 72.30 & $5,639.40$ \\
\hline 2 & 5 & 3 & 24.00 & 23.10 & 5 & 9 & 112.41 & 8767.98 \\
\hline 3 & 10 & 6 & 18.00 & 16.95 & 9 & 4 & 43.72 & $3,410.16$ \\
\hline 4 & 20 & 12 & 18.00 & 16.91 & 8 & 4 & 43.88 & $3,422.64$ \\
\hline 5 & 15 & 9 & 20.00 & 19.20 & 8 & 4 & 45.36 & $3,538.08$ \\
\hline
\end{tabular}

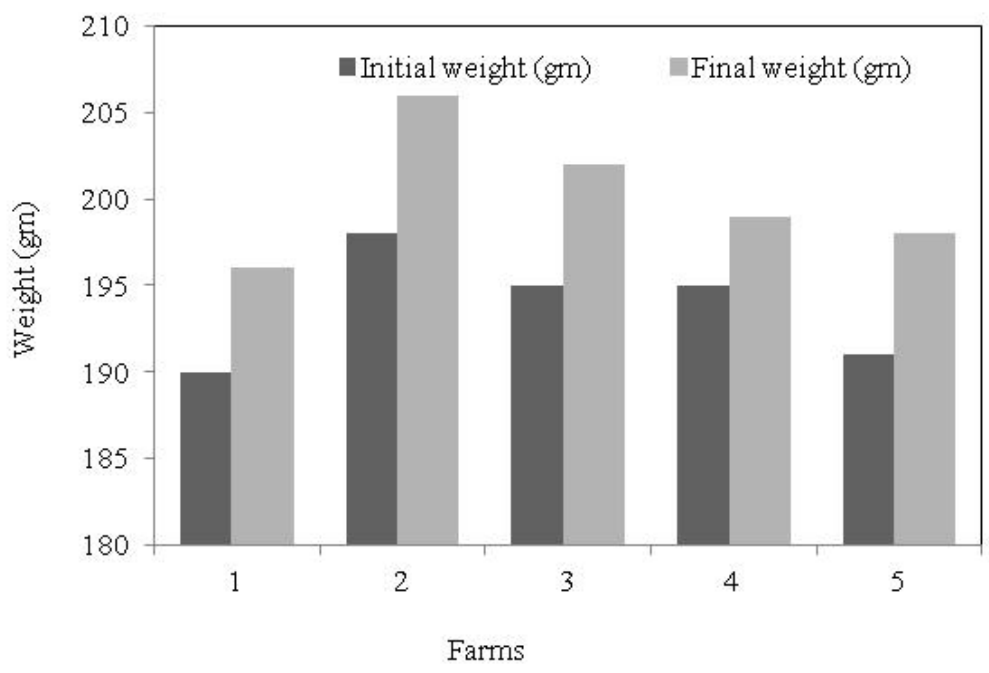

Fig. 1. Body weight (gm) gain of mud crabs within 14 days fattening period.

Acknowledgments: The author is very grateful to Caritas Australia for providing financial support to implement the community based adaptation project in coastal areas. The author would like to express gratitude to all project members and farmers who helped during data collection. 


\section{LITERATURE CITED}

CHANDRA, K., PAUL, A. and DAS, D. 2012. A survey on the production and marketing of mud crab, Scylla serrata (Forskal, 1755) in the south-western part of Bangladesh. International Research Journal of Applied Life Sciences 1(3): 44-55.

FERDOUSHI, Z. and XIANG-GUO, Z. 2010. Economic analysis of traditional mud crab (Scylla sp.) fattening in Bangladesh. Marine Research and Aquaculture 1(1):5-13.

HUSSAIN, M.Z. 2014. Issues and challenges. In: Hussain, M. Z. (eds) Bangladesh Sundarban Delta Vision 2050: A First Step in its Formulation - Document 2: A Compilation of Background Information. IUCN, Bangladesh Country Office, Dhaka, Bangladesh. pp. 85-101.

ISLAM, M.S. and WAHAB, M.A. 2005. A review on the present status and management of mangrove wetland habitat resources in Bangladesh with emphasis on mangrove fisheries and aquaculture. In: H. Segers and K. Martens (eds) Aquatic Biodiversity. II: The Diversity of Aquatic Ecosystems. Springer, Netherlands. pp 165-190.

LIONG, P.C. 1992. The fattening and culture of mud crab (Scylla serrata) in Malaysia. In: C. Angell (ed.) The Mud Crab: Report of the Seminar on the Mud Crab Culture and Trade, Surat Thani, Thailand, November 5-8, 1991, Bay of Bengal Program: 185-190.

UDDIN, M.S., SHAH, M.A.R., KHANOM S. and NESHA, M.K. 2013. Climate change impacts on the Sundarbans mangrove ecosystem services and dependent livelihoods in Bangladesh. Asian Journal of Conservation Biology 2(2): 152-156.

ZAFAR, M. 2004. Culture of mud crab Scylla serrata in the coastal area of Bangladesh. DFID-SUFER Project Report, Institute of Marine Science, University of Chittagong, Chittagong, Bangladesh, pp. 6-16.

ZAFAR, M. and SIDDIQUI, M. Z. H. 2000. Occurrence and abundance of four Brachyuran crabs in the Chakaria Sundarban of Bangladesh. The Chittagong Univ. J. Sci. 24(2):105-110.

(Manuscript received on 30 January, 2016; revised on 12 June, 2016) 